\title{
Experiencias y emociones de las parteras con relación al sistema formal de salud en México
}

\author{
Experiences and emotions of midwives in relation to the formal health system in Mexico
}

Karina Xóchitl Atayde Manríquez

Universidad Autónoma del Estado de Morelos - México

Morelos, México

karina.ataydeman@uaem.edu.mx

Luz María González-Robledo

Universidad Autónoma del Estado de Morelos - México

Cuernavaca, México

luz.gonzalez@uaem.edu.mx

\section{RESUMEN}

El estudio buscó conocer la experiencia y las emociones en la práctica de la partería, en el estado de Morelos, bajo el contexto del modelo médico hegemónico. Se realizó un estudio cualitativo, apoyado en el método etnográfico, y tomando como referencia las narrativas de las propias parteras mediante entrevistas en profundidad. Los principales resultados del estudio muestran que 1) la experiencia de las parteras las ha encaminado a desarrollar y mantener prácticas que tienen una lógica distinta al modelo médico alopático hegemónico; 2) las parteras cuidan de manera significativa la dimensión emocional de las mujeres en la atención al embarazo, parto y posparto, con sensibilidad y respeto; al tiempo que 3) se mostró que dichos conocimientos y prácticas son deslegitimados desde la lógica hegemónica de la medicina alopática. El estudio concluyó que es necesario tener una mayor y mejor comprensión de la forma en la que trabajan las parteras y buscar generar espacios de diálogo con el sistema formal de salud, a fin de generar políticas inclusivas, de reconocimiento y de respeto para ellas, en tanto que de esa manera es posible apoyar a la salud materno infantil en beneficio de la sociedad.

Palabras clave: emociones; experiencia; parteras; conocimientos tradicionales; medicina tradicional.

\section{ABSTRACT}

The study sought to know the experience and emotions in the practice of midwifery, in the state of Morelos, under the context of the hegemonic medical model. A qualitative study was carried out, supported by the ethnographic method, and taking as a reference to the narratives of the parties themselves through in-depth interviews. The main results of the study were that 1 ) the experience of the parties has led them to develop and maintain practices that have a different logic than the hegemonic allopathic medical model; 2) midwives practice a logic that considers the emotional dimension in a significant way in the care of women, with sensitivity, respect, and care; while 3 ) it was shown that such knowledge is delegitimized from the hegemonic logic of allopathic medicine. The study concluded that it is necessary to have a greater and better understanding of the way in which midwives work and to seek to generate spaces for dialogue with the formal health system, in order to generate inclusive policies, of recognition and respect for them, in so much so that in this way it is possible to support maternal and child health for the benefit of society.

Keywords: emotions; experience; midwives; traditional knowledge; traditional medicine. 


\section{INTRODUCCIÓN}

La salud materno infantil es un tema que ha ocupado a los gobiernos de todo el mundo por ser un importante indicador del desarrollo social de un país o región. Es tal su importancia, que la Organización de las Naciones Unidas (ONU) en la Cumbre del Milenio del año 2000 incorporó, dentro de la estrategia denominada Objetivos de Desarrollo del Milenio, el mandato de reducir la mortalidad materna y la mortalidad infantil para el 2015, con el fin de contribuir a la atención de las necesidades y derechos fundamentales, particularmente de las mujeres y de los niños, así como de reducir las brechas de la pobreza extrema (Gil et. al., 2006). Pese al avance alcanzado y a los esfuerzos realizados, no se logró la meta establecida en esta materia, por lo que se mantienen como propósito en los Objetivos de Desarrollo Sostenibles (ODS) 2030 (Atkin et. al., 2016). En México, durante las dos últimas décadas se han realizado múltiples acciones desde diversas esferas institucionales y sociales para reducir la mortalidad materna e infantil, logrando importantes avances en ello (Freyermuth, 2015). Sin embargo, aún hay mucho por hacer para cumplir las metas establecidas en los acuerdos internacionales.

En México la política gubernamental de atención al binomio madre-hijo se ha dirigido principalmente a garantizar la atención prenatal, así como del parto por personal especializado (médicos) en espacios hospitalarios (Medina-Espino, 2013) en los que no hay cabida para las parteras. Si bien el país tiene una larga historia de partería tradicional (Sánchez \& Lakato, 2018) y técnica (Carrillo, 1999) y durante muchos años fueron las principales figuras en la atención al embarazo, parto y posparto, se quedaron fuera de los espacios de la atención formal institucionalizada por las normas y políticas establecidas por el Estado desde los años cincuenta del siglo pasado (Carrillo, 1998). Es por ello que el número de parteras en el territorio nacional, ha disminuido drásticamente y con ello se han ido perdiendo conocimientos, prácticas, usos y costumbres milenarias. Las parteras que aún persisten, se encuentran en condiciones poco favorables en el sistema formal de salud (Carrillo, 1999).

Estudios internacionales como el de Atkin et. al. (2016) han demostrado que "invertir en personal de partería competente, motivado y respaldado, es una estrategia costo-efectiva para mejorar la calidad de la atención y los resultados maternos y neonatales" (2016 p.5) y que si su atención estuviera disponible y fuera accesible para las mujeres y sus bebés se podrían evitar dos tercios de las muertes maternas y la mitad de las de recién nacidos, si este personal contara con una buena formación y el apoyo necesario del sistema de atención de la salud (Atkin et al, 2016). De esta manera, la atención con la colaboración de las parteras podría coadyuvar a la mejora de la salud materno-infantil en el territorio nacional y, particularmente, en aquellas zonas donde el recurso humano en salud es escaso. Contrario a ello, se las está dejando fuera del sistema de atención y sin políticas claras que las apoyen, con la consecuente tendencia a su extinción, lo cual es un contrasentido respecto a los planteamientos internacionales y a las necesidades actuales de atención.

Hoy en México es posible encontrar diversos tipos de parteras, que podemos clasificar en dos grupos: las tradicionales que se entrenan de manera empírica y las técnicas con educación formal. Las tradicionales, son aquellas que adquieren el conocimiento por tradición oral y generalmente es transmitido de una generación a otra; utilizan en su quehacer la herbolaria medicinal, habitualmente realizan acciones manuales (sobadas, masajes, etc.); manejan conceptos que forman parte de los valores comunitarios que se ubican en la cosmovisión prehispánica (Castañeda-Camey, 1992) y buscan mantener su autonomía respecto al sistema formal de salud. Por otro lado, encontramos a las parteras que se han formado de manera técnica, las que han asistido a la universidad para estudiar una carrera (Licenciatura en enfermería y obstetricia [LEO] o Licenciatura en Salud Reproductiva y Partería Profesional) y también existe la especialización en enfermería perinatal (se lleva a cabo posteriormente a la licenciatura). También, es posible encontrar parteras que se han formado en escuelas alternativas que buscan preservar las tradiciones como es el caso de las escuelas Nueve Lunas o CASA, a través de lo que denominan un modelo educativo innovador integrando ciencia (conocimiento y técnica), arte (combinación de creatividad, intuición y criterio), tradición (rituales culturales y conocimientos ancestrales de las leyes y elementos de la naturaleza) y espiritualidad (visión del parto y nacimiento como momentos sagrados) (Nueve Lunas, 2020). Este modelo de formación lo fundamentan en la premisa de que el embarazo y el parto son acontecimientos saludables y fisiológicos de la vida con una dimensión espiritual. Las primeras y las últimas realizan su quehacer como parteras fuera del sistema formal de salud, las segundas ejercen su profesión como enfermeras generales (no atienden 
partos) en las instituciones de salud. Incluso es común encontrar mujeres que han transitado de una formación a otra acorde a sus intereses y posibilidades.

Actualmente, la principal relación que tienen las parteras tradicionales y las técnicas entrenadas en escuelas alternativas con el sistema formal de salud mexicano es mediante capacitaciones ofertadas por los Servicios Estatales de Salud (SESA), mismas que se han establecido para ellas y a las cuales se encuentran obligadas a asistir si quieren seguir ejerciendo como parteras. Ambas figuras (parteras tradicionales y técnicas) trabajan bajo distintas lógicas (al modelo médico especializado y hospitalocéntrico) y se enfocan en la atención de mujeres con embarazos normales y partos de bajo riesgo que corresponden al primer nivel de atención en salud.

Derivado de todo lo anterior, el presente artículo tiene como objetivos: 1) explorar diversas facetas que configuran la experiencia actual de las parteras en Morelos en la atención al embarazo, parto y posparto; 2) establecer el significado y el manejo de las emociones de las parteras en su experiencia de atención al embarazo, parto y posparto; e 3 ) indagar el trato que reciben y las relaciones que construyen las parteras con el personal del sistema formal de salud en torno al ejercicio de su quehacer ocupacional.

\subsection{Experiencia, emociones y modelo médico hegemónico: referentes teórico-conceptuales}

El estudio de los recursos humanos para la salud ha sido objeto de múltiples y variados abordajes y perspectivas como la epidemiología, los sistemas, servicios y políticas de salud, la economía, entre otras disciplinas. Incluso, ha sido objeto de diversas exploraciones sociológicas (Freidson, 1978; Domínguez-Alarcón, 1979; Fernández J. et. al., 2010). Estudiar a las parteras en el contexto actual (social, económico, político y cultural) de México con la lente de las ciencias sociales, puede contribuir significativamente a la comprensión de este grupo ocupacional y su aportación a la salud materno-infantil. Por lo tanto, hemos considerado tres categorías teórico-analíticas para el estudio de las parteras en Morelos: la experiencia (Scott, 2001), las emociones (Ariza 2020; López, 2013; Bericat; 2000) y el modelo médico hegemónico (Menendez, 1988).

En primer lugar, la experiencia como elemento teórico, permite acercarse a una comprensión y forma de mirar específica de los sujetos de estudio, en este caso las parteras. Este constructo se retoma de Johan Scott (2001), Chandra Tlalpade Mohanty (2008) y Shari Stone-Mediatore (1999). En su conceptualización, si bien comparte la palabra con su uso coloquial, no se ciñe a él. La experiencia resulta particularmente pertinente para el estudio del fenómeno que aquí nos ocupa, en tanto que este marco ha sido acuñado para hablar de realidades ignoradas, deslegitimadas y subalternas, sobre las que se despliega un poder mordaza que subestima, no mirando a dichos sujetos, a sus condiciones, ni a sus historias de existencia. La experiencia es llamada a dar testimonio de formas de dominio y opresión que producen sujetos subalternos (Trevisacce, 2016).

Dicho concepto es una herramienta epistémica útil acorde al objetivo del presente estudio ya que destaca, desde sus orígenes, la crítica al conocimiento neutral, ofreciendo en cambio un conocimiento situado que da cuenta del contexto y posición de quién se habla y de quién habla (Trebisacce, 2016). En ese sentido, el caso de la partería en México, tiene en su historia reciente la subalternidad, la otredad; se ha desarrollado a partir de una práctica ancestral de forma tradicional en casi todo el país. Sin embargo, desde hace décadas, no han tenido el reconocimiento debido, ni un espacio de actuación claramente definido dentro del sistema formal de salud a escala nacional (Atkin et. al., 2016). Además, ha ocurrido de manera progresiva un silenciamiento del diálogo con y acerca de la partería, en el cual han sido despojadas de la palabra y su autoridad ha sido transferida al dominio del modelo que hegemoniza.

Por otra parte, el estudio de las emociones - como una herramienta o categoría de análisis - (Ariza, 2020; Ariza, 2016; Bericat, 2000; 2016; López, 2013; Le Bretón, 1999; Sabido, 2011), se incluyó en el presente estudio por dos razones. Primero, porque al entrar al campo de investigación se hizo evidente la importancia y el interés que las parteras tienen de trabajar dando centralidad a las emociones de las mujeres a quienes atienden. Segundo, por considerar que tal perspectiva puede aportar a un conocimiento social más integral, en este caso, el de la atención al binomio madre-hijo que ofrecen las parteras. A decir de Marina Ariza (2016), considerar la dimensión emocional en la investigación social forma parte de un esfuerzo amplio de recuperación de una dimensión analítica largamente soslayada en el conjunto de las ciencias sociales y las humanidades (Ariza, 2016). Las emociones han ido adquiriendo sucesivamente importancia, en razón 
a que se ha reconocido su valor heurístico para entender la vida social e individual, así como la necesidad de tomar en cuenta la parte afectiva de los sujetos para comprender mejor los fenómenos en los que se encuentran inmersos (López, 2013).

Finalmente, para una mejor comprensión del entorno social, el complejo mundo de la salud, la enfermedad y la atención y los procesos interactivos en los que se despliegan las parteras en su quehacer, se consideró pertinente incorporar al referente teórico el modelo médico hegemónico desarrollado por Menéndez (1988), por el cual se entiende al conjunto de prácticas y saberes conocidos como medicina científica que ha establecido como subalternas al resto de prácticas y saberes para identificarse como la forma legitimada de atender la enfermedad (Menéndez, 1988).

Dicho modelo es una propuesta conceptual pertinente para evaluar la manera en que la medicina secundariza o anula otros saberes, generalmente populares, en el campo de la salud. Así como también excluye diálogos menos jerárquicos en la relación médico paciente (Huerta, 2015) y tiene una perspectiva fragmentaria que no mira de forma integral a la persona y ve a la enfermedad como enemiga más que como un proceso orgánico. En la presente investigación se ha enfatizado la característica de que además es un modelo específicamente alopático. Ello en tanto que es bajo esa lógica como se abordan las maneras de curación institucionalmente, presentándose como la forma de atención por excelencia y dejando en silencio a otras prácticas de atención en salud (Aguirre, 2016). Dicho modelo se centra en un creciente control biotecnológico y una organización protocolizada y mecanizada del trabajo fomentando la medicalización de características biológicas o eventos vitales que no necesariamente requieren «curación», como es el embarazo y el parto (García, 2017).

Derivado de todo lo anterior, el presente artículo tiene como objetivo responder las siguientes preguntas: ¿Cómo se caracteriza y configura la experiencia actual de las parteras en Morelos en la atención al embarazo, parto y posparto? ¿Qué significado tienen y cómo manejan las emociones las parteras en su experiencia de atención al embarazo, parto y posparto? ¿Cómo se relacionan y son tratadas las parteras por el sistema formal de salud en torno al ejercicio de su quehacer ocupacional?

\section{Metodología}

Se desarrolló un estudio cualitativo apoyado en el método etnográfico. El trabajo de campo se desarrolló entre los meses de febrero a noviembre de 2019. Se utilizaron como técnicas de recolección de información la observación y las entrevistas en profundidad para lo cual se desarrollaron guías de tópicos y se utilizó el diario de campo. La selección de la muestra fue por conveniencia (Tarrés, 2013) de acuerdo con criterios de inclusión predeterminados: a) dedicarse a la partería, b) residir en Morelos y c) aceptar participar en el estudio. Se buscó obtener información con la mayor riqueza y variabilidad de informantes.

El tamaño de la muestra se definió a partir de los casos ricos en información, lo cual permite la comprensión profunda del fenómeno, no siendo tan importante (para la aproximación cualitativa) el número de participantes, puesto que no se busca la generalización de los datos (Vela, 20013: p. 65) y por criterio de saturación teórica (Guest, 2006). La muestra final quedó conformada por ocho informantes: 3 parteras tradicionales, 2 técnicas y 3 parteras en formación.

Las entrevistas fueron grabadas en audio digital después de obtener el consentimiento informado de las participantes. Las categorías y sub categorías de análisis se presentan en la tabla 1.

Tabla 1. Categorías y sub-categorías de estudio

\begin{tabular}{|c|l|}
\hline Categorías & \multicolumn{1}{c|}{ Sub-categorías } \\
\hline \multirow{5}{*}{ Experiencia } & $\begin{array}{l}\text { Motivaciones para dedicarse a la partería } \\
\text { Formación y entrenamiento } \\
\text { Cuidado del espacio para el trabajo de parto } \\
\text { Labores y prácticas en la atención al embarazo y parto } \\
\text { Prácticas tradicionales (herbolaria, masajes, reboso, temazcal) } \\
\text { Alumbramiento/placenta }\end{array}$ \\
\hline
\end{tabular}




\begin{tabular}{|l|l|}
\hline \multirow{3}{*}{ Emociones } & $\begin{array}{l}\text { Afectos } \\
\text { Emociones positivas (pertenencia, aceptación, seguridad, satisfac- } \\
\text { ción) } \\
\text { Emociones negativas (culpa, rechazo, vergüenza, miedo, ansiedad) } \\
\text { Vínculos seguros e inseguros (con las mujeres que atienden, con sus } \\
\text { colegas, con el sistema de salud, con la comunidad) } \\
\text { Manejo de las emociones de las mujeres en la atención del parto }\end{array}$ \\
\hline Modelo médi- & $\begin{array}{l}\text { Biologicismo alopático } \\
\text { hegemónico }\end{array}$ \\
& $\begin{array}{l}\text { Relación asimétrica médico-paciente } \\
\text { salud } \\
\text { Profesionalización formalizada } \\
\text { Racionalidad científica como criterio para excluir otros modelos y } \\
\text { prácticas } \\
\text { Expansión sobre áreas problemáticas las cuales medicaliza } \\
\text { Normatización de la salud y la enfermedad } \\
\text { Tendencia al control social e ideológico }\end{array}$ \\
\hline
\end{tabular}

Fuente: Elaboración propia para la presente investigación

El procesamiento de la información comenzó con la transcripción de las entrevistas. El análisis de los datos fue guiado a través de códigos organizados por temas y subtemas definidos y complementado con las observaciones registradas en el diario de campo. Durante todo el proceso se siguió un enfoque flexible en la integración y sistematización de nueva información para la configuración de la experiencia y las emociones de las parteras en el ejercicio de su quehacer en un contexto específico.

\section{Resultados}

El perfil sociodemográfico de las parteras se muestra en la tabla 2. De las ocho parteras entrevistadas, dos son técnicas (formadas por otras parteras en un curso formal, pero sin reconocimiento oficial en México), tres son tradicionales y tres están en formación (dos de ellas en escuelas alternativas y una cursando la Licenciatura en la Escuela de Enfermería de la Cruz Roja). De esta última categoría, la que está cursando sus estudios en la Escuela de Enfermería de la Cruz Roja, ha recibido entrenamiento en partería con parteras tradicionales, ha tomado cursos e incluso contribuyó a abrir una escuela de formación de parteras en la Ciudad de México. La mayoría de ellas, llegaron de otros lugares de la república y se establecieron en municipios de Morelos.

Tabla 2. Perfil sociodemográfico

\begin{tabular}{|c|c|c|c|c|}
\hline Tipo & Edad & Escolaridad & Entrenamiento & Municipio \\
\hline Técnica & 62 & Media superior & $\begin{array}{l}\text { Partera de EU, cursos varios y parteras } \\
\text { tradicionales }\end{array}$ & Tepoztlán \\
\hline Técnica & 72 & Media superior & $\begin{array}{l}\text { Partera de EU, cursos varios y parteras } \\
\text { tradicionales }\end{array}$ & Cuernavaca \\
\hline Formación & 29 & Media superior & Escuela de nueve lunas y otras parteras & Tepoztlán \\
\hline Tradicional & 65 & $\begin{array}{l}\text { Licenciatura } \\
\text { trunca }\end{array}$ & Madre y escuela de enfermería & Tepoztlán \\
\hline Tradicional & 29 & Media superior & Parteras tradicionales y Nueve Lunas & Amatlán \\
\hline Formación & 25 & $\begin{array}{l}\text { Licenciatura } \\
\text { en curso }\end{array}$ & Escuela de la Cruz Roja & Cuernavaca \\
\hline Tradicional & 82 & $\begin{array}{l}\text { Sin educación } \\
\text { formal }\end{array}$ & Abuela y médico de su comunidad & Temixco \\
\hline Formación & 28 & $\begin{array}{l}\text { Licenciatura } \\
\text { en curso }\end{array}$ & $\begin{array}{l}\text { Parteras tradicionales, parteras profesiona- } \\
\text { les y escuela de la Cruz Roja }\end{array}$ & Tepoztlán \\
\hline
\end{tabular}

Fuente: Elaboración propia para la presente investigación 


\subsection{La Experiencia de la partería}

La configuración de la experiencia de las parteras se encuentra íntimamente conectada con dimensiones de su trayectoria vital. En ella se incluyen diversos aspectos que resultan significativos para ellas, así como una serie de criterios y acciones que no necesariamente comparten por la formación o el entrenamiento recibido o por la escuela a la que asistieron, más bien obedece a una lógica propia, a una manera distinta de entender el embarazo, el parto y el posparto y a formas de entender aspectos como el tiempo, los espacios, los cuidados, las emociones y, en general, los focos en los que ponen su atención en el ejercicio de su labor.

Uno de los aspectos que conforman la experiencia y que puede tomarse como punto de partida, es la motivación que las hizo dedicarse a la partería. Se observó que la dimensión ocupacional está íntimamente ligada a su historia biográfica. Varias de las entrevistadas aluden a un tipo de vocación, un llamado que las llevó a ser parteras. También refirieron la influencia familiar, principalmente en los casos de quienes se asumen dentro de la partería tradicional. Hablan de haber estado presentes en nacimientos, lo cual sentó precedentes significativos para buscar entrenarse como tales. Así mismo, el nacimiento de sus propios hijos, para algunas de ellas, las motivó a apoyar a otras mujeres.

Otra motivación se relaciona con aspectos políticos, entendidos como el «control» y «capacidad de decisión» de las mujeres frente al parto. En ese sentido, las parteras toman posiciones prácticas al menos en dos rutas. La primera, hace alusión a una forma de empoderamiento que las parteras buscan promover en las mujeres a quienes atienden para que ellas tengan en sus manos el poder de tomar sus decisiones en torno al parto. Esto lo hacen, por ejemplo, mediante la herramienta que llaman «plan de parto» buscando retomar lo que la embarazada espera y dando equilibrio con lo que puede ser más favorable según la experiencia y conocimientos de la partera; pues consideran que antes del alumbramiento se les retira la capacidad de decidir respecto al tipo de parto que prefieren y son otras personas (generalmente el médico) quien lo elige, muchas veces bajo criterios diferentes a las indicaciones clínicas o a las necesidades de las mujeres (intereses particulares). La segunda, apunta a una forma de hacer justicia a las mujeres. Consideran que hay principios y derechos que las mujeres deben tener; lo refieren a aspectos como tener silencio y calma durante el trabajo de parto, intimidad, a que puedan estar con su pareja o con las personas de su confianza. Así mismo, contrastan su práctica a la de los médicos en función a que, en ocasiones, éstos llevan a practicantes a auscultar las partes íntimas de las mujeres sin su consentimiento previo. También consideran básico el respeto a las creencias de la mujer que pare, sean religiosas o de cualquier otro tipo, pero se interesan en conocerlas y respetarlas.

Otro elemento que configura su experiencia, es el tipo de formación para el ejercicio de su oficio. Las parteras tradicionales, señalan haberse formado de manera empírica. Una de ellas, cuya abuela era partera quería aprender, pero su abuela le decía que era una niña y no debía «ver cochinadas». Al lado de donde habitaba llegó a vivir un médico y desde la edad de ocho años le permitió irse acercando al grado de participar, a esa corta edad, en su primer parto. Hoy tiene más de ochenta años y sigue atendiendo partos. Una de ellas, se formó con su mamá quien toda su vida se había dedicado a la partería. Después intentó estudiar enfermería en una universidad cuya carrera duraba tres años, sin embargo, a pesar de su interés debió dejar sus estudios un año antes de terminar por falta de recursos económicos. Actualmente continúa atendiendo partos.

Las parteras técnicas que participaron como informantes, tuvieron una formación que adquirieron desde diversos ámbitos. Dos de ellas se formaron con una partera que llegó desde Estados Unidos a vivir al municipio donde ellas residían y les dio una capacitación de tres años y medio. Sin embargo, no pudieron obtener una certificación, pues, aunque a decir de ellas, la Secretaría de Salud se había comprometido a entregarles un documento no les cumplió el acuerdo. Otra de las parteras, aún cuando tiene menos de 30 años de edad ha recibido entrenamiento en varias escuelas en distintos estados del país e, incluso, ayudó a constituir una escuela de partería en la Ciudad de México. Pese a ello, como aún no tiene un documento que avale sus estudios y aunque ya tiene años atendiendo partos, decidió cursar la Licenciatura en Salud Reproductiva y Partería que ofrece la Escuela de Enfermería de la Cruz Roja de Morelos, que es de las pocas instituciones que ofrecen educación formal en esta área en el país. Quienes se están formando en esta institución, refieren que hay pocas parteras dando clases y, que más bien, reciben una instrucción más apegada al modelo médico. 
El cuidado del espacio para el trabajo de parto, es el tercer elemento que conforma la experiencia de las parteras. Para ellas es fundamental la preparación del sitio donde van a atender el alumbramiento y éste puede ser un lugar reservado por ellas mismas (como casas de parto) o como sucede en la mayoría de los casos, en los hogares de quienes van a parir. Ello implica la construcción y armonización de cuestiones técnicas como el tamaño del lugar, la disposición del mobiliario (lugares limpios, ventilados, con iluminación tenue), la disponibilidad de recursos (desde alimentos o bebidas adecuadas hasta implementos que puedan favorecer la relajación, como el rebozo, aceites para masaje, entre otros), lo cual dialogan con las mujeres en las consultas prenatales y realizan una visita a la casa de la embarazada para acordar los requerimientos necesarios y la manera como se utilizarán. Además de elementos físicos, las parteras observan cuidadosamente aspectos que implican el cuidado emocional de las futuras madres en la que, al estar en las casas, buscan acompañarlas en encontrar su espacio de calma, seguridad y confort. Todo ello tiene implícita una labor y una sensibilidad emocional profunda en cada una de ellas, pues si bien no se han formado como psicólogas, su propia experiencia, las ha llevado a desarrollar conocimientos, habilidades y aptitudes para dar soporte y contención a las mujeres.

Las actividades y prácticas que realizan las parteras en la atención a las mujeres, es otro de los elementos que conforman su experiencia. Si bien no existe una estructura estandarizada que establezca la forma de atender a la parturienta, sí existen una serie de prácticas que son mayormente compartidas. En la atención al embarazo refieren que les gusta conocer a quienes atienden, entrevistarse con ellas en profundidad varias veces, meses antes del momento del parto. Conocerlas previamente les da la oportunidad de explorar sus expectativas, sus temores, sus dudas y las relaciones con su entorno físico y familiar.

El tema del manejo del dolor es un aspecto que tratan expresamente durante el embarazo, generalmente enseñan ejercicios y formas de respiración a las mujeres. Ofrecen paños calientes, masajes, formas de relajación y otros elementos en busca de mitigar el dolor. La percepción de las parteras en torno a éste es diversa entre quienes se entrevistó. La mayoría refiere que es una cuestión muy personal en cada mujer; algunas consideran que el dolor no es algo necesario en el parto; otras consideran que si no lo sienten no habría manera de que sepa que ya se acerca el momento del parto. La mayoría coincide en que existen estrategias que pueden apoyar a cada mujer de manera específica. Una de las prácticas relacionadas con el manejo de dolor que promueven, es la libre deambulación de la parturienta, por considerar que es algo que favorece la labor de parto. Durante la labor del parto, no limitan el consumo de bebidas y alimentos, sino que lo permiten según lo requieran las mujeres sugiriendo cosas específicas y ligeras. En relación a la ropa que debe llevar la mujer durante el trabajo de parto no sugieren una en particular (como la bata hospitalaria), sino prendas que se encuentren limpias y sean cómodas para la mujer.

Por otra parte, el uso de la herbolaria durante el embarazo, parto y posparto es una práctica acostumbrada por las parteras. Por generaciones, las han utilizado para la atención de las mujeres con distintos fines, como mejorar la calidad de la sangre durante el embarazo, buscar iniciar el trabajo de parto, detener una hemorragia durante el parto o ayudar a que los órganos regresen a su estado original en el posparto. Sin embargo, las parteras refieren que los médicos que las capacitan les prohíben explícitamente su uso, como exigencia y condición para mantener el permiso que les dan para mantener su práctica, lo cual se materializa a través de la autorización para otorgar las actas de alumbramiento. Debido a la prohibición de su uso, hay quienes las han dejado y han ido perdiendo el conocimiento de sus propiedades, hay otras que buscan rescatar esos conocimientos y hay quienes silencian su utilización. Este aspecto es objeto de discusión entre la partería y el modelo médico alopático y es un debate pendiente que debe darse de manera suficientemente amplia y conclusiva para garantizar, por una parte, el respeto a los usos y costumbres en torno a la herbolaria, y por otra la seguridad de las mujeres. Una de las parteras se refiere a este aspecto así:

\footnotetext{
...no permitirles actuar como ellas saben, ¿prohibir el uso de plantas? ¿Si las saben usar? Lo mejor sería hacer investigación sobre plantas. México tendría que hacer eso, si tiene toda una cultura de herbolaria, eso está haciendo China, está evidenciando científicamente sus plantas. Y lo están usando en los hospitales. Nosotros tenemos aquí falta de medicamentos y ino usamos nuestras plantas? Pero bueno. Uno es eso. Y la otra es, híjole, voy a decir algo muy fuerte pero realmente el sistema quiere aniquilar a las parteras, les pone una serie de obstáculos y de obstáculos que lo que quiere es quitarlas. No puede, pero esa es la tirada (Entrevista a partera en 2019).
} 
En México, el rebozo tiene un uso tradicional. Para las parteras es un instrumento de masaje útil para destensar partes específicas del cuerpo o para realizar lo que denominan el «manteo», que sirve para relajar a la mujer y al bebé en el acompañamiento posparto. Para las entrevistadas, tiene también una dimensión simbólica, conformando una especie de identidad y siendo una forma de resistencia al modelo médico hegemónico, pues les han pedido que no los usen para la atención a las mujeres. Sin embargo, para ellas tiene mucho sentido el uso práctico y también la importancia identitaria de ser parteras, usar y portar su rebozo.

El temazcal2, por otra parte, se utiliza después del parto, en lo que llaman cierre posparto, que consiste en un baño de vapor caliente. Aunque esta labor es ancestral, hoy en día se realiza de una manera más práctica para las mujeres en sus propias casas, con una tina que llevan las parteras con agua caliente y con mezclas de más de 10 hierbas. Después del baño las acuestan y utilizan el rebozo para comprimir el cuerpo de la mujer comenzando por la cabeza y bajando parte por parte, haciendo una presión que resulta agradable. Algunas de las parteras refieren que esta labor no solo tiene efectos físicos en el cuerpo de la mujer sino efectos emocionales, que buscan descansar el cuerpo de las labores del cuidado que ahora despliegan como madres y combatir cuestiones como la depresión posparto, ayudando a "nacer a la nueva madre".

Los masajes se utilizan de distintas formas en la partería, durante el embarazo generalmente es para acomodar a los bebés cuando se encuentran en posiciones desfavorables para el parto, también poco antes del momento del nacimiento usan aceites y masajes sobre el periné para evitar desgarros y masajes en distintas partes del cuerpo para relajar la musculatura y favorecer el parto, también puede ser usado como un soporte para la madre y para quien nace.

En cuanto llega el bebe, las parteras procuran realizar un corte tardío del cordón umbilical. En algunos casos esperan a que deje de pulsar. Es una práctica que se sugiere como positiva en la medicina basada en evidencia (Junquera, 2003). También suele ser un momento en que el papá o algún miembro de la familia interviene. La mayoría de las entrevistadas lo consideran como una forma de involucramiento de terceros en el proceso y ocurre a elección de la parturienta y de su núcleo familiar. El cordón en algunos casos, para algunas de las parteras, es procesado y preservado en tintura o cápsulas y utilizado como medicina y pueden realizar la misma práctica con la placenta.

El manejo de la placenta es un tema que tiene viarias aristas importantes a considerar. Las parteras tienen la costumbre de permitir el alumbramiento de ésta dándole tiempo a salir, o usando algún tipo de hierba cuando es necesario para ayudar a la expulsión de la misma. No tienen por costumbre jalar la placenta o introducir la mano para extraerla (lo cual ha sido una práctica médica por mucho tiempo y cada vez con más evidencia científica de ser una rutina nociva) (Cochrane, 2020). Para las parteras la relación con la placenta es un vínculo, comentan que buscan mirarla, que así saben que está completa, siendo como un símbolo de algo que se ha logrado. Enterrar la placenta es una costumbre en México, puede ser sembrada en un árbol de la casa de quien nace o en algún lugar de la comunidad. Hoy en día las parteras continúan acompañando costumbres y preferencias de las mujeres con relación a la placenta; hay quienes la comen después del parto por considerar que tiene efectos benéficos para la madre y para quien nace. Finalmente, posterior al nacimiento, las parteras colocan al bebé junto a su madre, piel a piel, buscando ese contacto lo antes posible. Uno de los propósitos es que se establezca la lactancia y se apoye el vínculo familiar. Esa es también una práctica avalada por la medicina basada en evidencia (Cochrane, 2020) y por organismos como la OMS (Fernández et al., 2005).

\footnotetext{
$1 \quad$ Es el nombre que recibe una prenda de vestir triangular o rectangular usada en México. También es usado en otros lugares de Centroamérica y América del sur. Recibe otros nombres como chal, fular. En el país se utiliza como una prenda sobre los hombros de las mujeres, también para cargar a los bebés e incluso para cargar y transportar otros objetos.

$2 \quad$ El temazcal es el nombre que recibe en México un baño de vapor que forma parte de rituales ancestrales empleados por la medicina tradicional con propósitos de desintoxicación y medicinales mediante la combinación con hierbas. Existen variantes, sin embargo, generalmente se crean espacios cerrados en los que se introducen las personas, al centro hay un espacio en el que se meten piedras que han sido puestas al fuego. En ese momento se meten al centro del espacio y se les vierte agua y hierbas para que las personas comiencen a sudar. A veces hay cantos y reflexiones u oraciones. Se busca hacer un recorrido por los reinos de la naturaleza (mundo mineral, vegetal, animal y humano). Después de lo cual se sale del espacio a manera de renacimiento. En ocasiones también beben tés para desintoxicar e hidratar el cuerpo. En el caso de las mujeres generalmente se utiliza en el posparto para guardar calor en el cuerpo.
} 
Los atisbos de la experiencia que hasta aquí se han trazado, muestran múltiples facetas de las parteras, pero, sobre todo, evidencian una serie de capacidades que pueden ofrecer como una ruta para contribuir a la atención materno-infantil. Al mismo tiempo, posibilita el apoyo en procesos de salud en los que no se requiere forzosamente un espacio hospitalario, cuando son embarazos normales o de bajo riesgo y que presagian un parto sin complicaciones, que no precisan medicalización y hospitalización, y en cambio, pueden ser atendidas con un trato sensible, razonable y cuidadoso como el que la experiencia de las parteras puede ofrecer. Es también una condición de cuidado a la cultura y tradición de México y el respeto a formas distintas de conocimiento.

\subsection{Las emociones en torno al quehacer de la partería y su relación con la atención a las mujeres}

Como parte de las entrevistas y observaciones preliminares se notó que un eje fundamental de su trabajo se encontraba en conexión con un tipo de labor emocional dirigido a las mujeres a quienes atienden y también cierto trabajo emocional sobre sí mismas. Esta categoría hace referencia, por una parte, al manejo de las emociones que realizan las parteras con las mujeres en el transcurso del parto y a la importancia que dan al manejo de sus propias emociones, para el buen desempeño de su tarea.

La labor de las parteras consiste en cumplir una serie de actividades asociadas al abordaje del proceso biológico que implica el nacimiento. Sin embargo, para ellas existe un aspecto imprescindible en esta labor: la observación de las emociones de las mujeres a quienes atienden, bajo la consideración de que van a establecer las condiciones más o menos propicias para tener un parto saludable, incluso refieren que es un apoyo para que una mujer no llegue a una cesárea innecesaria o que no buscó, ya que al encontrarse relajadas es más favorable para un parto natural, contrario a si se encuentran abrumadas o tensas. Esta labor, parte de la observación y de la experiencia en la atención a múltiples mujeres y también de la experiencia personal, que puede mirarse en la práctica de la partería tradicional y la técnica e incluso en el currículo de algunas de las escuelas de partería.

Para algunas de ellas, el trabajo emocional tiene un carácter político en torno a la salud, el bienestar y los derechos de las mujeres. Consideran que el reconocimiento de lo que sienten las mujeres no es solo información de utilidad para el momento del parto sino, sobre todo, una herramienta para las mujeres mismas, que les otorga conciencia sobre los procesos de su cuerpo, sensibilidad para observar sus propias necesidades y tener confianza en sí mismas. Varias de las parteras entrevistadas consideran que hay relaciones (amistades y familia) de las mujeres embarazadas a las que pueden o no conocer personalmente, pero sí les interesa saber si esas relaciones que las mujeres establecen tienen un significado en la emoción de la mujer al momento de ser atendida.

De acuerdo con los testimonios recabados, las emociones mayormente observadas por las parteras en las mujeres a quienes atienden se encuentran relacionadas con la alegría, el miedo, el dolor y el coraje (comúnmente entendido más como una fuerza que las impulsa que como un enojo). En múltiples ocasiones, éstas se entremezclan y se asocian a la esperanza del nacimiento del bebé que viene y las parteras buscan comprender tales emociones y acompañarlas para «desanudarlas» que no se dificulte el fluir del parto o que produzca tensión muscular que se manifieste en una complicación al momento de tener contracciones o en imposibilidad para relajarse; condición que es de gran importancia para las parteras en el momento del alumbramiento. Las referencias emocionales de tipo positivo realizadas por las parteras se encuentran asociadas a la búsqueda de efectos que apoyen al nacimiento involucrándose personalmente.

La gestión emocional se ha vuelto una forma identitaria de las mujeres parteras, en tanto que es una aspecto que observan y cuidan durante todo el proceso. Ello contrasta con el contexto de atención materno infantil del sistema formal de salud, que se enmarca en continuas denuncias de violencia obstétrica desplegada por diversos profesionales médicos y personal de enfermería y el incremento de cesáreas, muy por encima de los estándares marcados por agencias internacionales como la OMS. Procesos que prescinden de la consideración de las emociones de las mujeres. En una dimensión más personal, a las parteras les importa saber cómo fue el nacimiento de la mujer a quien van a atender, si la mujer embarazada asocia su nacimiento con alegría, miedo, dolor, soledad, por si esa emoción pudiera vivificarse en el momento en que nazca su bebé. Las parteras entrevistadas refieren que buscan saber si las mujeres a quienes van a atender sienten, por ejemplo, miedo; también quieren conocer a qué le temen (a lo desco- 
nocido, a la muerte etcétera). Así mismo esperan comprender de ellas las emociones que tienen y cuáles son las estrategias vitales con las que cuenta cada mujer o a las que está habituada a recurrir.

Otra de las prácticas compartidas por las parteras tiene relación con el acompañamiento familiar y de pareja que facilitan e incluso propician. Las entrevistadas generalmente promueven que alguna persona o personas acompañen a la mujer que va a parir, particularmente, en el momento del parto sea la pareja, la madre o a quien elija la mujer que va a parir. Es un tema que les implica una labor y el compromiso de conocer también, previamente al parto, a quien va a acompañar y mostrarle la manera en que puede apoyar, los límites y las cosas que pueden pedírsele, lo que se espera con su presencia y lo que no sería prudente. Al respecto han ido construyendo estrategias pues no es una tarea simplemente positiva, sino que depende de quien llega y la manera en que lo hace.

\subsection{La partería y el modelo médico alopático hegemónico}

El concepto de modelo médico hegemónico de Menéndez (1988) fue útil para advertir cómo la biomedicina secundariza otros saberes en el campo de la salud y excluye un diálogo más horizontal, menos jerárquico a los miembros de la relación médico-paciente (Huerta, 2015). Ello se observó en el trabajo que realizan las parteras, quienes hacen su labor bajo una visión y una lógica distinta al modelo médico. Pese a ello deben cursar sus estudios o atender las capacitaciones que son realizadas por médicos y no por parteras en los espacios en los que reciben adiestramiento.

Todas las parteras refirieron que solicitan a las mujeres a quienes atienden estudios de laboratorio. Sin embargo, refieren que dichos estudio son únicamente un referente porque, además, es necesario ver a la mujer que se tiene en frente más allá de las medidas estandarizadas que califican como anormal lo que sale de determinado patrón. En cambio, utilizan formas de alimentación y terapias o tratamientos alternativos para mejorar las condiciones de salud de las mujeres durante el embarazo. Por otra parte, las parteras refieren que buscan establecer relaciones de diálogo y reconocimiento de las fortalezas y los límites de las mujeres a quienes atienden. Tratan de conocer la historia física pero también las relaciones sociales y afectivas de las mujeres y sus familias generando vínculos de confianza mutua. De manera que las interacciones son menos asimétricas entre la mujer a quien entienden y ellas. Es común que hagan equipo con parteras con quienes se complementan o con otro tipo de terapeutas que pueden aportar al conocimiento de las mujeres o con doulas que son mujeres que se han especializado en la gestión emocional y de confort en la atención al parto.

Las parteras establecen relaciones en las que buscan que las mujeres tengan posturas activas en su propia atención; que tomen acción y responsabilidad de sus procesos. Ponen atención a los aspectos que prefieren las embarazadas y sus familias, en tanto que de ahí retoman conocimientos acerca de cómo se sentirán más seguras y tranquilas durante el parto. También enseñan ejercicios y masajes para realizar en sus casas sea por ellas mismas o por sus parejas o familiares para favorecer condiciones físicas y anímicas adecuadas.

En cuanto a la formalización del estatus de parteras, es el Estado el que norma el alcance de sus funciones y responsabilidades; sin embargo, la falta de apoyo gubernamental y de la organización de las mismas partera en agremiaciones que aboguen por ellas mismas, ha contribuido al retraso en la conformación de la partería como una profesión. Así, las parteras, mantienen un estatus de subordinación e inferioridad en el sistema formal de salud.

Para hablar de la construcción de la otredad y su contexto, es necesario observar las formas de control dirigidas a las parteras. Por ejemplo, el aspecto que se encuentra asociado al tema de las actas de alumbramiento. Dichas actas, precursoras del acta de nacimiento, han implicado una de las formas de control de las autoridades sobre las parteras. Su «buen comportamiento», que en muchos de los casos implica dejar de seguir sus usos y costumbres o los tratamientos que ellas daban tradicional o regularmente a las mujeres a quienes atendían, las habilita para continuar otorgando dicho registro y ser validado por el registro civil. Otro ejemplo que ellas refieren es que no se les permiten usar medicamentos como la oxitocina (en casos de emergencia) aún cuando ésta hace parte de la medicina alopática. La otredad experimentada por las parteras no se limita a una experiencia personal, lo que ya puede resultar una experiencia dolorosa y un camino difícil. También se encuentra implicado el sometimiento por parte del modelo médico alopático hegemónico sobre otros conocimientos, en este caso, el conocimiento y prác- 
ticas de las parteras. Esto sucede como un proceso estructural que oprime un conocimiento, sin siquiera, un análisis real de lo que está limitando o lo que está promoviendo, sino que, simplemente funciona como un mecanismo ciego, cruzado por prejuicios y desconocimientos de su trabajo; dejándolas de lado, como las otras, como desconocedoras, ignorantes, en tanto que se les mide desde una lógica médica alopática. De alguna manera, se les tolera y se les adoctrina, mediante capacitaciones, a figuras cercanas a la forma de tratar, ser y practicar el modelo hegemónico, se les enseña para «hacerlas mejores», y esto es -en ese criterio- ser lo más parecidas a los médicos.

Una siguiente dimensión, son las relaciones que las parteras establecen de manera inmediata o mediata con algunos médicos. De estas relaciones que, si bien son tan diversas como médicos y parteras existen, se puede hablar de dos principios interactivos básicos. El primero de ellos lo constituye una figura de carácter y reflejo de lo institucional. A este nivel, los médicos personifican las normas institucionales. El segundo principio interactivo lo encontramos en lo personal; aquí hay, dicho de manera general, dos sub-formas básicas de dicho principio, una primera en la que, las parteras hacen acuerdos con algún médico para que sea quien atienda a la mujer en caso de que sea preciso llevar a cabo una cesárea. La segunda de las sub-formas, es según las referencias de las parteras, la que establecen de manera casual al encontrarse con lo médicos. En este nivel es común que las parteras refieran cuestiones de desconocimiento o franco maltrato.

Así mismo, existe una constante introducción de factores externos a su labor como los que les son otorgados en los espacios de capacitación, en los que promueven una lógica de medicalización (establecimiento de protocolos fuera de su práctica, las «recomendaciones», por ejemplo, de pedir determinados estudios a las madres entre otros factores similares) las mantienen en constante comparación bajo los criterios médicos y no bajo su propia lógica de actuación. Aunado a ello, se complejiza el hecho de que en los casos en que las parteras son incorporadas a espacios de atención pública están subordinadas a enfermeras licenciadas o a médicos (especialistas o generales). Dicha situación las mantiene en constante medición de parámetros ajenos y bajo una dinámica que jala permanentemente hacia la dinámica médica, sin reconocer que obedecen a diferentes lógicas y posturas y que eso tiene un sentido. Entonces, de alguna manera, son infantilizadas, tratadas como no médicas, sin una identidad propia, como imperfectas. Así refieren percibir los tratos recibidos.

Las parteras han experimentado una transformación que ha transitado desde atender la mayoría de los embarazos y partos en su comunidad, hasta la llegada de la atención gubernamental gratuita, con implicaciones importantes en su mercado laboral, ya que han disminuido sus posibilidades de trabajo y se ha desvirtuado la valía de su labor. Dicho cambio ha implicado, en un sentido general, haber pasado de ser consideradas socialmente como mujeres sabias a ser consideradas como una forma de auxiliares. Hoy la comunidad de las parteras en su entorno recibe cierto reconocimiento, aún cuando la propia cultura y costumbres se han ido transformando; aun cuando en los espacios en los que establecen contacto con médicos o con instituciones del sistema de salud, las parteras llegan a experimentarse como otras y ajenas e incluso a percibirse maltratadas.

\section{DISCUSIÓN}

Para el estudio fue importante la observación de la experiencia de las parteras, con las capas que ello implica, reconociendo que no es necesario enumerar rígidamente o priorizar una u otra para mirar que es el grosor, la multiplicidad y las tensiones de la experiencia lo que las hace un recurso útil (Stone-Mediatore, 1999) para la atención materno-infantil, la comprensión diferente del quehacer de la partería y para realizar un acercamiento que procure resguardar los significados que ellas ofrecen. El concepto de experiencia, como refiere Stone-Mediatore (1999), facilitó la identificación de diálogos que conllevan tensiones entre el discurso ideológico y la experiencia misma. Ello implica contradicciones que son soportadas subjetivamente entre percepciones del mundo construidas ideológicamente (como en el caso del discurso médico que busca instruirlas) y reacciones a estas imágenes (respuestas de asunción o rebeldía) toleradas a múltiples niveles psicológicos y corporales (Stone-Mediatore, 1999). Las parteras con las que se establecieron diálogos tienen un discurso así arraigado en su propia experiencia física del parto, aunado la defensa de los derechos de las mujeres y a la búsqueda y acompañamiento del poder de decisión de cada una de quienes atienden como si de su propio cuerpo se tratara. 
La lucha ideológica al respecto es fuerte pues el de ellas es un discurso práctico, local, de voz en voz y de evento en evento; mientras que el otro lado del discurso parece decir que en la atención al parto normal son imprescindibles los hospitales y la atención especializada de tipo médico y que la decisión se encuentra en esas manos: ese discurso está presente en los medios de comunicación masiva (Estrada, 2015). Esto es aún más marcado por el uso del poder que se hace desde el reconocimiento de lo alopático como equivalente de lo científico, lo verdadero, lo mejor y único, aunado al silenciamiento y la subalteridad impuesto a las mujeres parteras por parte del sistema público de salud.

Scott (2001) ha referido que lo que puede contar como experiencia no es evidente, ni claro y directo, que está en disputa y que, por lo tanto, siempre es político (Scott, 2001). Ello es palpable en la interacción entre el sistema formal de salud y las parteras; en la experiencia silenciada de los efectos positivos físicos y emocionales en las mujeres atendidas, los tratos y labor desempeñada por las parteras tan acallada en el país vuelve a actualizar en este contexto la pregunta que hiciera Spivak (2003): ¿puede hablar el subalterno? y aún ésta resuena con mayor fuerza cuando se considera que la voz silenciada de las parteras, son también las voces de las mujeres a quienes atienden o quienes habrían querido ser acompañadas en su parto por una de ellas.

La naturaleza afectiva de la acción social, problematizada en el vínculo entre ésta y la afectividad; entre la acción racional instrumental y las emociones, posibilita abrir nuevas vetas de intelección de lo social (Ariza, 2020). En el caso de la partería muestra una perspectiva que va más allá del modelo hegemónico actual. Las narrativas experienciales de las parteras como un intento por tomar en cuenta tensiones dentro de la experiencia, reflejando tipos de acciones, de comunidad o de conciencia que tiene negada la articulación en el discurso hegemónico, (Stone-Mediatore, 1999) se vuelve en un problema social; en el que primero, se ha mostrado como dos discursos opuestos, más adelante se ha tornado en un silenciamiento, pero poco a poco éste se materializa en la tendencial a la extinción de una de esas vetas. A la par que el modelo médico gana terreno en la atención del binomio madre-hijo, las parteras lo van perdiendo. En consecuencia, el número de éstas se va reduciendo.

Algunos de los resultados obtenidos en el presente estudio coinciden con lo reportado en la literatura. Por ejemplo, Marín (2020) habla de la casa de partos como un espacio-temporal heterotópico, observado desde una visión foucaultiana que representa espacios y discursos que de alguna manera son «otros», en donde se encuentra implicada la transformación. Al respecto en la presente investigación se hace patente la forma de ser otras, la otredad en la que quedan las parteras respecto al sistema formal de salud (Coello-Velazco et al, 2019). También se encuentran similitudes con el estudio de Bottery y Bochar (2019), quienes concluyen que el trabajo de las parteras refuerza el poder activo que tienen las mujeres de parir de forma natural y espontánea y que en los espacios hospitalarios los médicos mantienen distancia emocional de los cuerpos y éstos son vistos como objeto de trabajo desprovistos de emociones.

\section{CONCLUSIONES}

El estudio permitió explorar las diversas facetas que configuran la experiencia actual de las parteras en Morelos en la atención al embarazo, parto y posparto. Mediante el método cualitativo de corte etnográfico utilizado en la investigación, se estableció el significado y el manejo de las emociones de las parteras en su experiencia de atención al embarazo, parto y posparto. Se logró indagar acerca del trato que reciben y las relaciones que construyen las parteras con el personal del sistema formal de salud en torno al ejercicio de su quehacer ocupacional.

Los alcances de la presente investigación estriban en conocer los elementos que configuran la experiencia actual de las parteras en Morelos, reconociéndose los procesos mediante los cuales se han encaminado a desarrollar y mantener prácticas que tienen una lógica distinta a la del modelo médico alopático hegemónico. El estudio permitió mostrar que las parteras cuidan de manera significativa la dimensión emocional de las mujeres atendidas, mediante prácticas concretas con sensibilidad y respeto. La investigación encontró que dichos conocimientos y prácticas son deslegitimados desde la lógica hegemónica de la medicina alopática.

Dadas las características metodológicas del estudio, éste presenta una serie de limitaciones. Por ejemplo, los resultados de la investigación requieren de una mayor profundización y un dialogo más amplio con otras investigaciones. Es necesario plantear nuevas preguntas de investigación que permitan ahondar en 
la comprensión del fenómeno social estudiado. Algunas líneas de investigación que quedan abiertas son: 1) incorporar las voces de las mujeres atendidas por parteras versus las atendidas por médicos alópatas en espacios hospitalarios; 2) recuperar los testimonios del mismo personal de salud en cuanto a la labor, ventajas y desventajas de la partería en México;3) conocer las perspectivas de quienes hacen las políticas públicas en salud con el fin de abrir el diálogo y permitir el entendimiento entre dos formas distintas de concebir y atender las necesidades de las mujeres en el embarazo, parto y posparto. Urge la generación de políticas inclusivas, de reconocimiento y de respeto para ellas, en tanto que de esa manera es posible apoyar a la salud materno infantil en beneficio de la sociedad.

\section{REFERENCIAS}

Aguirre, J. L. (2016). La auto-atención y el enfoque relacional. Archivos de Medicina Familiar y General, 13(1), 27-34. https://revista.famfyg.com.ar/index.php/AMFG/article/view/8

Ariza, M. (2016). Emociones, afectos y sociología: diálogos desde la investigación social y la interdisciplina, Universidad Nacional Autónoma de México (UNAM).

Ariza, M. (2020). Las emociones en la vida social: miradas sociológicas. Instituto de Investigaciones Sociales.

Atayde, M. K. X. \& González-Robledo L. M., (2019). Parto y habitus: un estudio sociocultural en mujeres en el estado de Morelos, FORHUM International Journal of Social Sciences and Humanities 1(1), 78-86 https://doi.org/10.35766/ jf19117

Atkin, L. C., Kehith-Brown, K., Rees, M. W., \& Sesia, P. (2016). Fortalecer la partería: Una deuda pendiente con las mujeres de México. Fundación John D. and Catherine T. MacArthur.

Bericat, A. E. (2000); La sociología de la emoción y la emoción en la sociología, Papers. Revista De Sociología, 62, 145176. http://dx.doi.org/10.5565/rev/papers/v62no.1070

Botteri, E., \& Bochar Pizarro, J. E. (2019). Saberes que conectan con el poder durante el parto: la partería tradicional en Morelos (México). Alteridades, 29(57), 125-135, https://doi.org/10.24275/uam/izt/dcsh/alteridades/2019v29n57/botteri

Carrillo A. M. (1998), Profesiones sanitarias y lucha de poderes en el México del siglo XIX. Asclepio, 50(2),149-168. https://doi.org/10.3989/asclepio.1998.v50.i2.340

Carrillo A. M. (1999), Nacimiento y muerte de una profesión. Las parteras tituladas en México. DYNAMIS. Acta Hispánica ad Medicinae Scientiarumque Historiam Illustrandam, 19, 167-190. https://ddd.uab.cat/record/33742.

Castañeda-Camey X. (1992). Embarazo, parto y puerperio: conceptos y prácticas de las parteras en el estado de Morelos. Salud Publica México, 34, 528-53. https://saludpublica.mx/index.php/spm/article/view/5615

Cochrane (2020, octubre). Biblioteca Cochrane, evidencia fiable, decisiones informadas, mejor salud. https://www. cochrane.org/es/evidence.

Coello-Velazco, A. P., González-Alonso, F., \& Velasco-Espinosa, E. (2019). Parteras tradicionales indígenas: El Derecho Educativo a las Pedagogías "otras” [Ponencia en Congreso]. VII Congreso Internacional y IV Congreso Nacional de Investigación en Derecho Educativo ARIIDE., Chiapas, México.

Domínguez-Alarcón, C. (1979), Para una Sociología de la profesión de enfermería en España. Revista Española de Investigaciones Sociológicas, 8,103-132. https://doi.org/10.2307/40182811

Estrada, M. D. A. (2015), La medicina como producción de subjetividad. Una aproximación a Michel Foucault. Escritos, 23(51), 331-355. http://orcid.org/0000-0001-8102-7229

Fernández, J., Barajas, G., y Barroso, L. (2010). Profesión, ocupación y trabajo: Eliot Freidson y la conformación del campo. Ediciones Pomares.

Fernández, R. C., Muñoz, B. Á., Rodríguez, S. F., \& Alba, R. H. (2005). Promoción de la salud basada en la evidencia: realmente funcionan los programas de salud comunitarios?. Atención primaria, 35(9), 478-483. https://doi. org/10.1157/13075472

Freison, E. (1978). La profesión Médica. Un estudio de sociología del conocimiento aplicado. Ed. Peninsula.

Freyermuth, Graciela (coordinadora) (2015); 25 años de buenas prácticas para disminuir la mortalidad materna en México. Experiencias de organizaciones de la sociedad civil y académica.

García, E. M. (2017). Hacia los partos empoderados: recuperando nuestros cuerpos secuestrados por la biomedicina. Dossiers feministes, (22), 87-106. ttps://www.raco.cat/index.php/DossiersFeministes/article/view/328066

Gil, D., Palma, M., Cantero, M., Ruíz, M., et al. (2006). El reto para la salud pública de los Objetivos de Desarrollo del Milenio: un enfoque desde la epidemiología política. Gaceta Sanitaria, 20, 61-65. https://doi.org/10.1157/13101091

Guest, G., Bunce, A., \& Johnson, L. (2006). How many interviews are enough? An experiment with data saturation and variability. Field methods, 18(1), 59-82. https://psycnet.apa.org/doi/10.1177/1525822X05279903

Huerta, B. L. (2015). La antropología médica y la medicina social: dos dimensiones necesarias para abordar los temas 
de salud enfermedad, Ciencia UANL Revista de divulgación científica y tecnológica de la Universidad Autónoma de Nuevo León, 18 (71), http://cienciauanl.uanl.mx/?p=2933

Junquera, L.M., Baladrón, J., Albertos, J.M., \& Olay, S. (2003). Medicina basada en la evidencia (MBE): Ventajas. Revista Española de Cirugía Oral y Maxilofacial, 25(5), 265-272. https://www.medigraphic.com/cgi-bin/new/resumen. cgi?IDARTICULO=19404

López, S. O. (2013). Cuerpo, salud, género y emociones: estudios diacrónicos y sincrónicos, Revista Electrónica de Psicología Iztacala, 16 (4), http://revistas.unam.mx/index.php/repi/article/view/43704

Marín, V. Y. (2020). Crear un intersticio sagrado para nacer. Un análisis antropológico de ejercicio de la partería profesional urbana en una casa de partos en México. Antrópica: Revista de Ciencias Sociales y Humanidades, 6(11), 257-281, http://orcid.org/oooo-0002-5018-232X

Medina-Espino, A. (2013). Políticas públicas en el ámbito federal para la atención de la mortalidad materna en México. Cámara de Diputados LXIII Legislatura. https://cutt.ly/shILnOP

Menéndez, E. L. (1998). Modelo médico hegemónico: reproducción técnica y cultural. Natura Medicatrix: Revista médica para el estudio y difusión de las medicinas alternativas, (51), 17-22. https://dialnet.unirioja.es/servlet/articulo? codigo $=4989316$

Mohanty, C. T. (2008); Bajo los ojos de occidente. Academia Feminista y discurso colonial. En, L. Suárez, \& A. Hernández. (Eds.): Descolonizando el Feminismo: Teorías y Prácticas desde los Márgenes (pp. 117-163), Editorial Cátedra.

Nueve Lunas (2020, octubre). Nueve Lunas S. C., Centro de iniciación a la partería Nueve Lunas http://parteriayconocimiento.com/cip/

Sánchez, R. G. \& Lakato H. (2018). Parterías de Latinoamérica. Diferentes territorios, mismas batallas, El Colegio de la Frontera Sur.

Scott, J. W. (2001). Experiencia. La ventana, 2 (13), 42-74, https://dialnet.unirioja.es/servlet/articulo?codigo=5202178

Spivak, G. C. (2003). ¿Puede hablar el sujeto subalterno? Orbis Tertius, 3(6). 297-364 https://cutt.ly/ghIL9Qg

Stone-Mediatore, S. (1999). Chandra Mohanty y la revalorización de la experiencia. Revista Hiparquia, 10(1), 85-109. http://www.hiparquia.fahce.unlp.edu.ar/numeros/volx/chandra-mohanty-y-la-revalorizacion-de-la-experiencia

Tarrés, M. L., (Coord.) (2013). Observar, escuchar y comprender sobre la tradición cualitativa en la investigación social. El Colegio de México/FLACSO Mexico.

Trebisacce, C. (2016). Una historia crítica del concepto de experiencia de la epistemología feminista. Cinta de moebio 3(5). 23-64. http://dx.doi.org/10.4067/S0717-554X2016000300004

Vela, P. F. (2013), Un acto básico de la investigación social: la entrevista cualitativa En: Tarrés, M., (coord.). Observar, escuchar y comprender sobre la tradición cualitativa en la investigación social (63-123). El Colegio de México/ FLACSO México.

\section{AUTORAS}

Karina Xóchitl Atayde Manríquez. Candidata a Dra. en Ciencias Sociales por la Universidad Autónoma del Estado de Morelos (UAEM), México, Maestra en Ciencias Sociales por la Universidad Autónoma del Estado de Morelos (UAEM), México, Licenciada en Economía por la Universidad Nacional Autónoma de México (UNAM), México. Principales líneas de investigación: Salud reproductiva, parto, partería, maternidades, género y masculinidades.

Universidad Autónoma del Estado de Morelos, México

Luz María González-Robledo. Doctora en Ciencias de la Salud Pública, Maestra en Administración de Salud. Estancia en Salud Internacional Harvard T.H. Chan School of Public Health. Profesora-investigadora de la Universidad Autónoma del Estado de Morelos (UAEM). Miembro del Sistema Nacional de Investigadores (SNI-CONACYT).

\section{Conflicto de intereses}

El autor(es) informa(n) ningún conflicto de interés posible.

Financiamiento

No existió asistencia financiera de partes externas al presente artículo.

Agradecimientos

$\mathrm{N} / \mathrm{A}$ 